ISSN-1729-521

\title{
Household Food Security Status of Marginal Farmers in Selected Storm Surge Prone Coastal Area of Bangladesh
}

\author{
Md. Ektear Uddin* \\ Dept. of Agricultural Extension and Rural Development, Patuakhali Science and Technology \\ University, Dumki, Patuakhali - 8602, Bangladesh \\ *Corresponding author and Email: ektear_pstu@yahoo.com
}

Received: 18 July 2011

Accepted: 26 May 2012

\begin{abstract}
The objective of the study was to understand and describe the household food security status of the marginal farmers in a selected storm surge prone coastal area of Bangladesh. The study also assessed the extent of livelihood vulnerability and coping strategies of the storm surge affected marginal farmers. To collect data from the 30 randomly selected respondents a pre-tested structured interview schedule was administered during 01 to 10 October 2010. The finding reveals that maximum marginal farmers were food insecured $(56.67 \%)$, while $30 \%$ were moderately food secured and only $13 \%$ were food secured. Though adequate food was available in local markets those were beyond affordability. The partial food security was due to poor food utilization in marginal farmers' family. The most three vulnerable options of livelihood for the marginal farmers were crop farming, fish farming and livestock farming. The respondent farmers adopted six self coping strategies and three assisted coping strategies to cope with the vulnerability and food insecurity. The self coping strategies were decreasing the number and size of daily meals, consumption of wild food, selling labour at very low rate, selling fixed and movable household assets, contracting new loan at a high interest rate and cultivation of short duration crop. On the other hand, assisted coping strategies include relief food, social network and begging.
\end{abstract}

Keywords: Coping strategy, food security, livelihood vulnerability, marginal farmers, storm surge

Bangladesh is a victim of global climate change. Bangladesh stands second among the twelve most cyclone prone countries of the world (Islam, 2011). Coastal regions of Bangladesh are the most vulnerable to flood, cyclone and storm surge. Coastal area comprises about 30 per cent of the country (Uddin et al., 2008). Among the coastal zones, the central zone comprises about one third of the total. During the years 1797 to 2010, Bangladesh has been hit by 64 severe cyclones, 35 of which were accompanied by storm surges (compiled from www.adpc.net). Among the storm surges about sixty percent hit the central coastal area of Bangladesh comprises the portion of Patuakhali, Barguna, Bhola, Barisal, and greater Noakhali district. Only in SIDR, damage and losses in Agriculture sector was 437.6 Million US\$ which was about 90 percent of total productive sector (GoB, 2008).

Since long the poor and landless people of Bangladesh have been experiencing food insecurity during the lean season of the year and during the natural disasters. Though the government declared Bangladesh as a food selfsufficient country very recently, it does not mean 
that Bangladesh is really a food secured country. National food security is achieved when all the people gained physical and economic access at all time to enough food for an active and healthy life (Reutlinger, 1987; USAID, 1995). According to FAO, food security exists when all people, at all times, have access to sufficient, safe and nutritious food to meet their dietary needs and food preferences for an active and healthy life (http://en.wikipedia.org/wiki/Food_security). Household food security is a multidimensional concept comprises food availability, economic access to food, and proper utilization of food to be synthesized in body. Household food security carefully looks at intra-household food distribution.

In a subsistence nature agrarian economy like Bangladesh, household food production has an important role to play in the quest for food security. The coastal zone especially the central coast does not have favourable agro-climatic environment for growing diversified crops because of natural disaster like cyclone, storm surge, heavy rainfall, flood, river bank erosion etc. together with soil salinity, low land topography and very transient winter. The major crops of the study area are reported as Aman rice, variety of pulses, sesame and oilseed. On the other hand, though vulnerable to natural disaster, fishing and fish culture have huge potential. However, due to less diversity in cropping system and limited employment scope for marginal farmers, the food insecurity is revealed to be chronic and far reaching.

The central coast experiences some small or big storm surges almost every year that cause heavy crop loss culminating into food insecurity. Rice is the prime food for common Bangladeshi and is not exception for the coastal people. The famers of that area cultivate mainly rain-fed local Aman rice and cultivate Aus rice on a limited basis. They are reluctant to high yielding Boro rice cultivation primarily because of late Aman rice, lack of fresh irrigation water, and lack of salt tolerant rice varieties. Hence, they heavily depend on local Aman rice to meet up the annual food demand. On the other side, the Aman period (July to November) is susceptible to heavy rainfall, flood, cyclone and storm surge. Hence, this zone is considered to be the rice deficit pocket. In general, it is considered that food security of a marginal farmer is better than that of a landless one. But what happens in marginal farm households when only one rice crop is damaged due to storm surge? An understanding of this phenomenon is needed. This study was therefore, undertaken: to (i) assess and describe the household food security status of marginal farmers of a selected storm surge prone coastal area; (ii) determine the extent of livelihood vulnerability of marginal farmers due to storm surge; and (iii) determine the coping strategies of marginal farmers in food vulnerable situation caused by the storm surges.

The study was conducted in two severely storm surge affected village- Charkhali and Golkhali of Mirjagonj Upazila under Patuakhali District. A list of 100 marginal farmers were made in advance. From the list, $30 \%$ farmers were selected randomly as the sample of the study. To collect data from 30 respondents a structured interview schedule was used together with a case study. Data were collected by the researcher himself during 1 October to 10 October 2010.

For measuring food security, three dimensions were considered- food availability, food accessibility and food utilization. Four statements were set against each dimension as indicators of food security. Status of food security was measured on the basis of one's representation on a five point continuum of very high, high, moderate, low, not at all. A weight of $4,3,2,1$ and 0 were assigned for very high, high, moderate, low and not at all, respectively. Hence, food security score of a respondent varied from 0 to 48 , where 0 indicated highly food insecured and 48 indicated highly food secured. However, a Food Security Index (FSI) was also prepared based on the basis of frequency distribution of the respondents on 12 statements of the dimensions of food security. 


$$
\begin{gathered}
\text { FSI }=\left\{\left(f_{\mathrm{VH}} \times 4\right)+\left(f_{\mathrm{H}} \times 3\right)+\left(\mathrm{f}_{\mathrm{M}} \times 2\right)+\left(\mathrm{f}_{\mathrm{L}} \times 1\right)+\right. \\
\left.\left(\mathrm{f}_{\mathrm{NA}} \times 0\right)\right\} \\
\text { Where, } \mathrm{f}_{\mathrm{VH}}=\text { Frequency of 'very high' opinion } \\
\mathrm{f}_{\mathrm{H}}=\text { Frequency of 'high' opinion } \\
\mathrm{f}_{\mathrm{M}}=\text { Frequency of 'moderate' opinion } \\
\mathrm{f}_{\mathrm{L}}=\text { Frequency of 'low' opinion and } \\
\mathrm{f}_{\mathrm{NA}}=\text { Frequency of 'not at all' opinion }
\end{gathered}
$$

Thus, total FSI score for 30 respondents could range from $(30 \times 0)=0$ to $(30 \times 4 \times 12)=1440$ and of individual dimension it could vary from $(30 \times 0)=0$ to $(30 \times 4 \times 4)=480$. FSI was prepared with a view to compare the food security status among three dimensions of food security as well as to find out the most vulnerable dimension of food security of the respondent. During data entry, a series of checks were made for keystroke errors, duplicate entries and to ensure that the data were collected and enumerated correctly. Data analysis was conducted using SPSS software of 11.5 version.

The finding shows that highest proportion of the marginal farmers $(56.67 \%)$ was food insecured, while about one third of them were moderately secured (30\%) and only $13.33 \%$ were food secured (Table 1).

The food security index (FSI) also shows that though food was available in market, the marginal famers had limited economic access. The limited economic access was due to the poor socio-economic condition of the marginal farmers. The most important thing is that the marginal farmers' family had poor food utilization capacity. This happened due to poor or sometimes no knowledge on human nutrition and proper food processing together with unhygienic water and sanitation use. The cumulative effect of all these ultimately was exhibited on the total household food security of the coastal marginal farmers (Fig. 1).

Storm surge is one of the most disastrous events that disrupted normal life and livelihood of the coastal marginal farmers almost every year. Sometimes storm surge makes the coastal people absolutely pauper - owing nothing for the next day. The findings of the present study reveal that there are four options of livelihood for the marginal coastal farmers (Fig. 2). Among them crop farming is most vulnerable to storm surge (Score 118). The storm surge sweeps the standing off crops and the rest portion encounters lodging and shuttering loss. Ultimately this causes entire crop failure as well as livelihood disruption of mono crop farmers. The second most vulnerable sector is fishing and/or fish farming (score 115). During fishing in a windy day, peoples affected by the storm surge and they lose their fishing traps, boats and even lose their valuable lives occasionally. On the other hand, due to a very high storm surge the captured fishes become free that causes a great loss to the farmers. The third most vulnerable sector of livelihood is livestock farming (score 88). During a big storm surge missing of livestock is a common phenomenon. The remaining livestock become vulnerable for food and shelter. Thus, storm surge makes the livestock farming more challenging in coastal areas. The least vulnerable livelihood option is day laboring (79). The marginal farmers, who have to depend on day labouring, pass a tough time during and immediately after the storm sure.

Historically, it is found that coastal people have a long experience of living with natural hazards like storm surge. People with their patience and courage adopted different strategies to live in this hazardous area. The findings of the study show that marginal farmers adopted two categories of coping strategies - self copping strategies and assisted copping strategies (Fig. 3). The group column graph shows that marginal farmers adopt six strategies by their own abilities to cope with food shock induced by the storm surge. The most frequently used strategy is_decrease in the size and number of meals. During the lean season all the marginal farm family members have to take less than a full meal every three times in a day or even one or two meals by turn, as for example one who takes meal at morning has to give up meal for noon. The second most important strategy is consumption of uncultivated food $(56.66 \%)$ from wild sources - like aroids, water lily, kolmi (Ipomoea aquatica), leafy weeds, sheath and inflorescence of road side banana etc. 
Table 1. Category of the storm surge affected marginal farmers according to food security score

\begin{tabular}{lcccccc}
\hline \multicolumn{1}{c}{ Category } & $\begin{array}{c}\text { Possible } \\
\text { range }\end{array}$ & $\begin{array}{c}\text { Observed } \\
\text { range }\end{array}$ & Number & Percent & Mean & SD \\
\hline Food insecured people $(<16)$ & & & 17 & 56.67 & & \\
Moderately secured people $(16-26)$ & $0-48$ & $12-31$ & 9 & 30.00 & 20.76 & 4.8 \\
Food secured people $(>26)$ & & & 4 & 13.33 & & \\
\hline Total & & & 30 & 100.00 & & \\
\hline
\end{tabular}

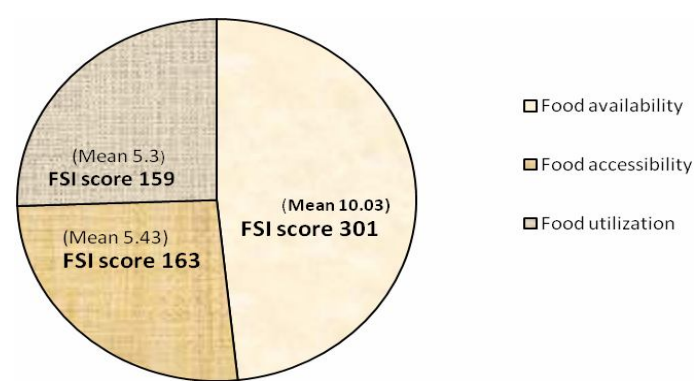

Fig. 1. Pie chart showing share of the each dimension to total household food security

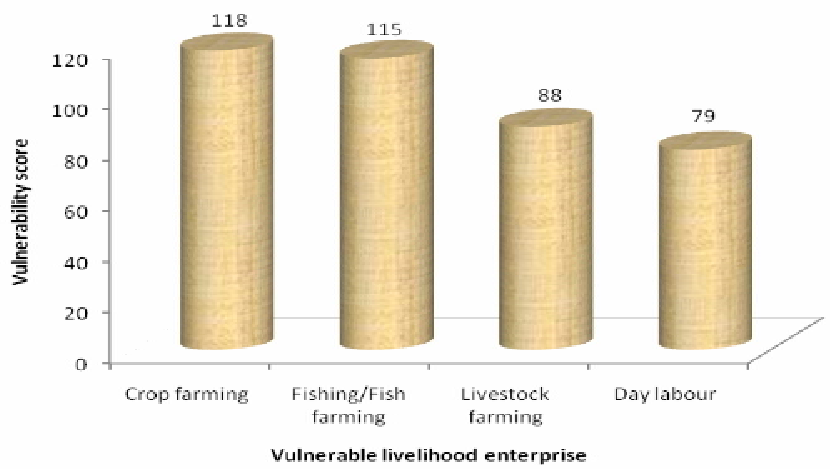

Fig. 2. Livelihood options of marginal farmers and their vulnerability to storm surge 


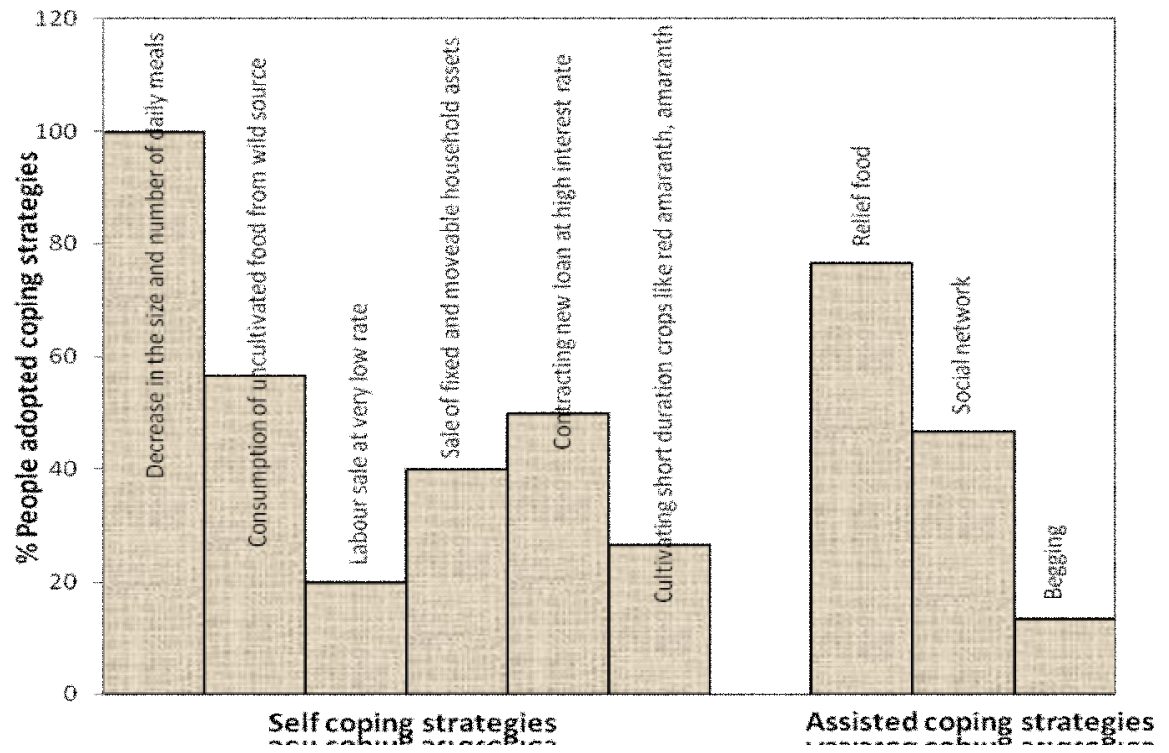

Fig. 3. Strategies taken by storm surge affected marginal farmers to cope with food insecurity

Half of marginal farmers take new loan and this is identified as third most important strategy. Many of them (40\%) sell their fixed and moveable assets to cope with food insecurity. Some of the marginal farmers cultivate short duration crops like red amaranth, amaranth, radish etc. as a midterm strategy. A few of marginal farmers $(20 \%)$ sell their day labour at a very low rate to earn their daily bread. Rana et al. (2009) and Rahman (2008) found more or less results in their study.

On the other hand, the second cluster of the Figure 3 shows that the marginal coastal farmers adopt three assisted coping strategies to get relief from food insecurity. Majority of the marginal farmers $(76.66 \%)$ take relief food to cope with stern food insecurity. They get food from individuals, NGOs and GOs both on a temporary and permanent basis eg. vulnerable group feeding (VGF). About half of them (46.66\%) get food assistance from their community peoples and relatives. A very few of them have to beg on the sly outside his locality.

The central coast of Bangladesh has been turned into an ideal hitting point of storm surge. This type of climate change impact makes the lives and livelihood of the coastal people more challenging. A great share of the coastal farmers is marginal and leads a subsistence life. Every year this evil storm surge snatches the standing field crops, fishes and livestock which disrupt their livelihood options. Small or big storm surge, however, crop farming has been reported as the most vulnerable livelihood option followed by fish and livestock farming. Accordingly majority (about 57\%) of the marginal farmers were food insecured. This insecured situation was aggravated due to limited economic access to food and poor food utilization skill. Pure drinking water is scarce and costly in this area. The sanitation system in the study area is not good and is exposed to open 
water source. Hence, morbidity in marginal farmers' family is high.

The storm surge affected marginal farmer's family copped with the situation primarily by sliming the size and number of daily meals together with food assistance from peers and relief. Many of them had to consume food from wild source. Finding no options half of the marginal farmers contact new loan with high interest. Hence, cropping pattern and farming system in this area should be changed with appropriate agricultural technologies through immediate initiative of respective government departments (Agriculture, Fisheries and Livestock). Moreover, to restructure the livelihood, government as well as service providing NGOs should provide credit free of interest for a cropping year. Moreover, NGOs can come forward with income generating options for the marginal farmers of the coastal area to increase their economic access to food. On the other hand, government should look into the matter of providing with pure drinking water and appropriate sanitation system seriously.

\section{References}

GoB, 2008. Cyclone Sidr in BangladeshDamage, Loss, and Need Assessment for Disaster Recovery and Reconstruction. Report prepared by the government of Bangladesh assisted by the International Development Community with financial support from the European Commission.
Islam, M. T. 2011. Climate Change and Future Agriculture. Dhaka: The Daily Ittefaq, 22 May, 2011.

Rahman, M. Z. 2008. Rural Poor in Sidr Affected Southern Bangladesh: How Secured are their Livelihoods? Bangladesh Journal of Extension Education, 20 (1\&2): 71-77.

Rana, S., Rahman, M. H. and Islam M. N. 2009. Food Security Strategies Followed by the Farmers of a Disaster Prone Haor Area of Kishoreganj District. Bangladesh Journal of Extension Education, 21 (1\&2): 133-140.

Reutlinge, S. 1987. Food Security and Poverty in Developing Countries. In: Food Policy, (eds). J. P. Gittinger et. al., Baltimore: John Hopkins University Press Limited.

USAID, 1995. Development Project Proposal. Draft Interim Guidelines for FY 1986 P. L. 480.

Uddin, M. E., Rashid, M. U. and Akanda M. G. R. 2008. Attitude of the Coastal Rural Youth towards Some Selected Modern Agricultural Technologies. Journal of Agricultural and Rural Development, 6 (1\&2): 133-138

www.adpc.net

http://en.wikipedia.org/wiki/Food_scurity 
